\title{
Left circumflex coronary artery occlusion due to a left atrial appendage closure device
}

\author{
András Katona ${ }^{1}$, András Temesvári² ${ }^{2}$ András Szatmári², Attila Nemes ${ }^{1}$, Tamás Forster ${ }^{1}$, Géza Fontos ${ }^{2}$ \\ ${ }^{1}$ Division of Invasive Cardiology, Department of Cardiology, Albert Szent-Györgyi Clinical Centre, Medical Faculty, University of Szeged, \\ Szeged, Hungary \\ ${ }^{2}$ György Gottsegen National Institute of Cardiology, Budapest, Hungary
}

Postep Kardiol Inter 2015; 11, 1 (39): 69-70 DOI: 10.5114/pwki.2015.49192

\begin{abstract}
A bstract
Nowadays, percutaneous left atrial appendage (LAA) closure is spreading, and a large number of patients with this procedure have concomitant coronary artery disease. With the presented case it could be concluded that coronary angiography is recommended before LAA closure.
\end{abstract}

Key words: left circumflex, occlusion, left atrial appendage.

Nowadays, percutaneous left atrial appendage (LAA) closure is spreading, and a large number of patients with this procedure have concomitant coronary artery disease [1]. This sort of coincidence is not rare. A 59-year-old male patient is presented herein who had undergone coronary angiography in 2003/2004 showing significant stenoses of left anterior descending and right coronary arteries. Left circumflex (CX) showed no significant stenosis at that time. Following percutaneous coronary intervention (PCI) he was free of angina for 10 years. Despite chronic atrial fibrillation, oral anticoagulant therapy was stopped due to repeated head contusions. Left atrial appendage closure was planned to reduce the risk of stroke. The shape of the LAA looked like a glove with a huge ostium. Based on the dimensions of the LAA, the appropriate size of cardiac plug $(23 \mathrm{~mm})$ was selected. During the positioning of the device, ECG results changed demonstrating ST-elevations (STE) representing the inferior left ventricular re-
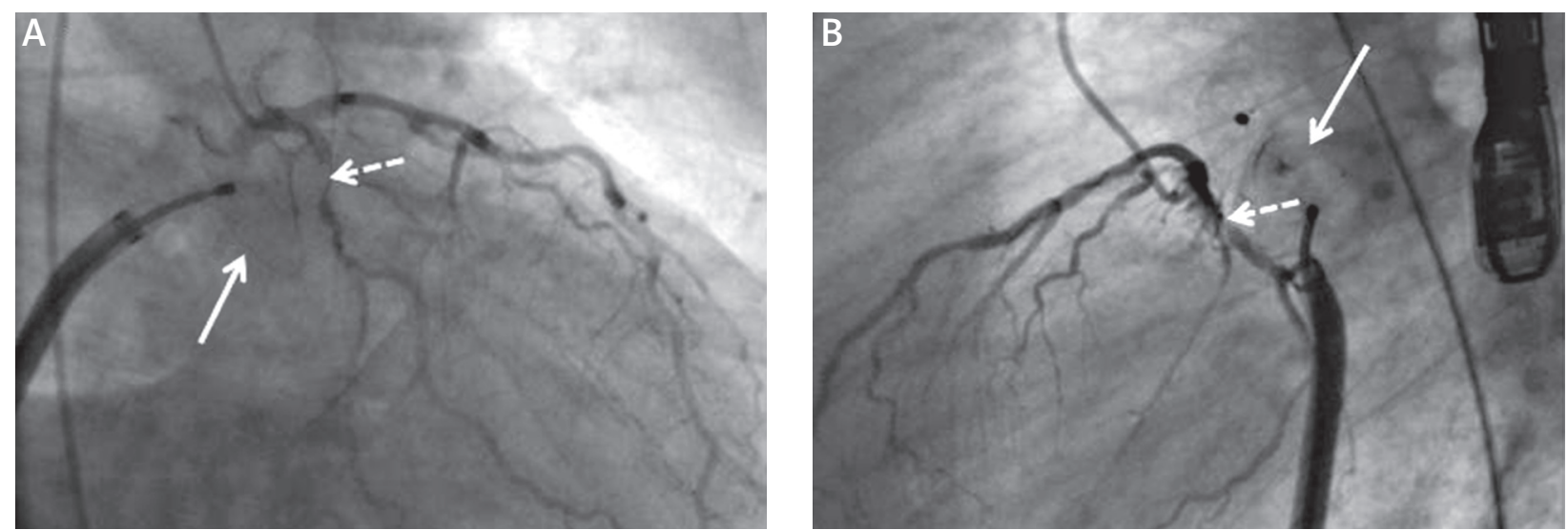

Figure 1. During positioning of closure device (white arrow), stenosis of circumflex coronary artery (dashed arrow) could be observed both in anteroposterior (A) and lateral views (B)

\section{Corresponding author:}

Attila Nemes MD, PhD, DSc, FESC, $2^{\text {nd }}$ Department of Medicine and Cardiology Centre, Medical Faculty, Albert Szent-Györgyi Clinical Centre, University of Szeged, H-6725 Szeged, Semmelweis 6, Hungary, P.O. Box 427, phone: +36 62545220 , fax: +36 62 544568,

e-mail: nemes.attila@med.u-szeged.hu

Received: 30.11.2014, accepted: 8.01.2015. 

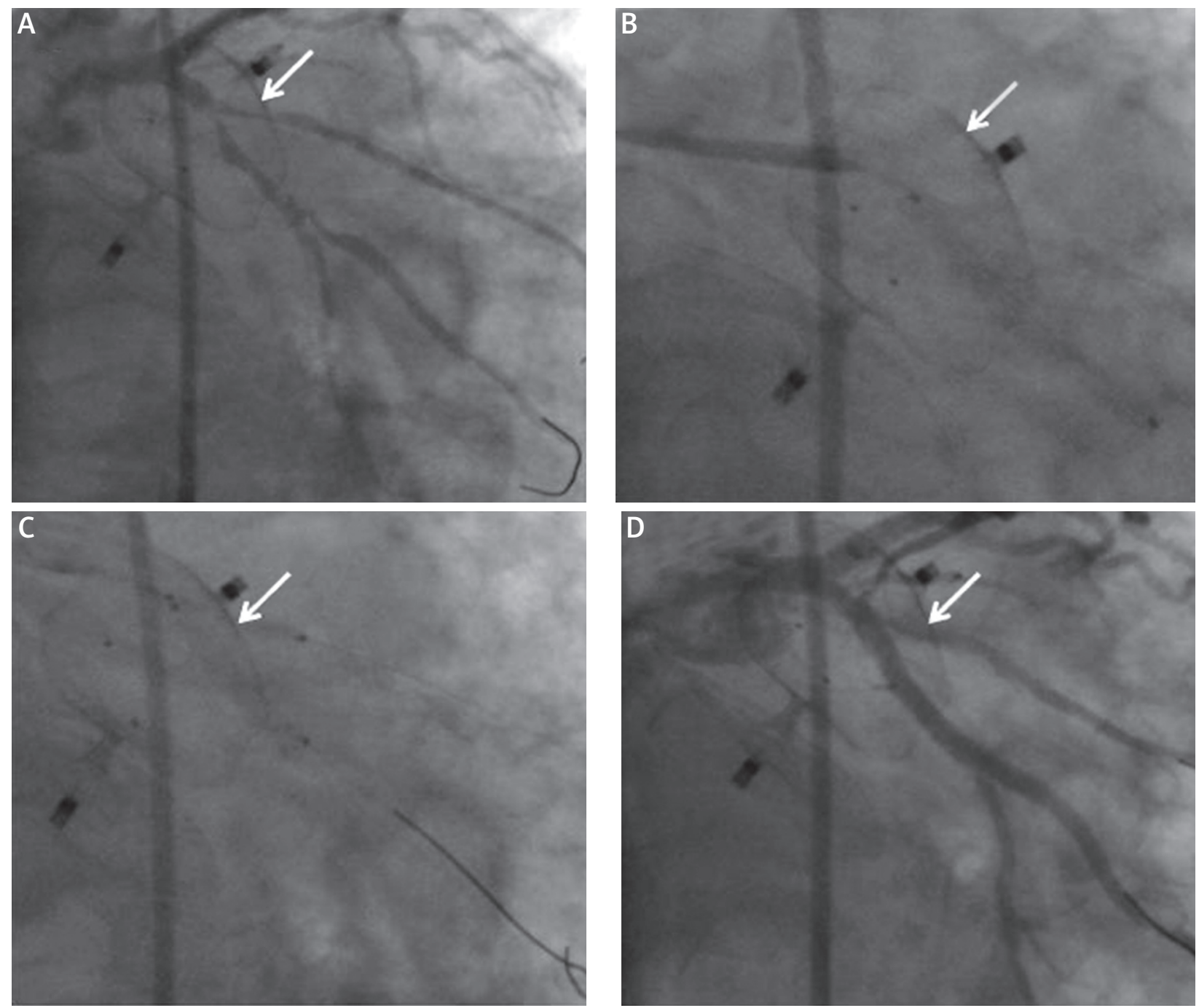

Figure 2. During percutaneous coronary angioplasty closure device (white arrow) has been repositioned (A), and a stent has been implanted into the circumflex artery (B) together with a kissing dilation (C). Final shot shows no stenosis of the circumflex artery (D)

gion. Coronary angiography showed compression of the proximal CX causing critical stenosis (dashed arrow) in anteroposterior (Figure $1 \mathrm{~A}$ ) and lateral views (Figure $1 \mathrm{~B}$ ); meanwhile, the device seemed to sit too superficially and not fully configured. Device was immediately retrieved, while STE disappeared. After repositioning of the device (white arrow) deeper in the ostium (Figure 2 A) $\mathrm{CX}-\mathrm{PCl}$ was performed with a drug-eluting stent (Figure 2 B) together with kissing dilation (Figure $2 \mathrm{C}$ ). At the end of the procedure no STE could be demonstrated, the device stayed in a fixed position, and finally no CX stenosis could be seen (Figure $2 \mathrm{D}$ ). It could be concluded that coronary angiography is recommended before LAA closure to clarify organic lesions.

\section{Conflict of interest}

The authors declare no conflict of interest.

\section{References}

1. Mangner N, Sandri M, Lurz P, et al. Left atrial appendage closure devices. Their role in 2013. Minerva Cardioangiol 2013; 61: 125-34. 